\title{
ESTUDO DE CASO SOBRE ACESSIBILIDADE EM ESCOLA MUNICIPAL, COLATINA-ES
}

\section{SANTO, Amabeli Dell}

Instituto Federal do Espírito Santo (IFES), e-mail: amabeli.dellsanto@ifes.edu.br

QUEIROZ, Virginia Magliano

Instituto Federal do Espírito Santo (IFES), e-mail: vimagliano@hotmail.com

SOARES, Marília Oliveira

Instituto Federal do Espírito Santo (IFES), e-mail: oliveira-marilia@hotmail.com

SALOTO, Mateus Bernardo Scussulim

Instituto Federal do Espírito Santo (IFES), e-mail: mateusscussulim@hotmail.com

\begin{abstract}
RESUMO
A inclusão social ainda é um desafio para a sociedade e seu estabelecimento exige mudanças profundas envolvendo profissionais de diversas áreas. Na arquitetura a efetivação da acessibilidade arquitetônica teve avanços significativos, com aumento do conhecimento e conscientização, entretanto, ainda há muito a ser feito. Considerando a obrigatoriedade de as escolas receberem alunos com necessidades educacionais especiais, o prédio escolar ganha relevância como instrumento de inclusão social e precisa passar por adaptações. Este trabalho, fruto de uma pesquisa de iniciação científica finalizada, avalia a acessibilidade em uma escola de ensino fundamental da rede municipal de Colatina-ES, por meio da realização de uma Avaliação Pós-Ocupação (APO), com os instrumentos: walkthrough, as built, checklist e entrevistas. A partir da análise dos dados coletados constatou-se um alto grau de inadequação do espaço escolar. Os impactos desta falta de acessibilidade podem gerar marcas, como o sentimento de não pertencimento, principalmente nos alunos que possuem necessidades especiais. Este estudo contribui para a reflexão no âmbito acadêmico e social, além de apresentar diretrizes para adequação do espaço analisado.
\end{abstract}

Palavras-chave: Acessibilidade, Avaliação Pós-Ocupação, Escola.

\begin{abstract}
Social inclusion is still a challenge for society and its establishment requires profound changes involving professionals from different areas. In architecture, the effectiveness of architectural accessibility has made significant progress, with increased knowledge and awareness, however, there are a lot to be done. Considering the obligation of schools to receive students with special educational needs, the school building gains relevance as an instrument of social inclusion and needs to undergo adaptations. This work, the result of a research with a scientific initiation completed, evaluates the accessibility in a primary school of the municipal network of ColatinaES, through a Post-Occupancy Assessment (APO), with the tools: walkthrough, built, checklist and interviews. From the analysis of the collected data, a high degree of inadequacy of the school space was verified. The impacts of this lack of accessibility can generate marks, such as the feeling of not belonging, especially in students who have special needs. This study contributes to the reflection in the academic and social scope, besides presenting guidelines for adequacy of the analyzed space.
\end{abstract}

Keywords: Accessibility, Post-occupation evaluation, School.

SANTO, A. D.; QUEIROZ, V. M.; SOARES, M. O.; SALOTO, M. B. S. Estudo de caso sobre acessibilidade em escola municipal, Colatina-ES. In: SIMPÓSIO BRASILEIRO DE QUALIDADE DO PROJETO NO AMBIENTE CONSTRUÍDO, 6., 2019, Uberlândia. Anais... Uberlândia: PPGAU/FAUeD/UFU, 2019. p. 1226-1236. DOI https://doi.org/10.14393/sbqp19112. 


\section{INTRODUÇÃO}

A escola é o ambiente em que as crianças aprendem a conviver em sociedade e descobrem que as pessoas não são todas iguais, aprendizado de suma importância para o seu desenvolvimento. Atualmente esta experiência é garantida pela inclusão escolar que propõe igualdade de oportunidade para todos.

No âmbito mundial, nas últimas décadas ocorreram muitos avanços em direção à essa inclusão, destacando-se a Declaração Mundial sobre Educação para Todos, instituída pela Organização das Nações Unidas para a Educação, a Ciência e a Cultura (UNESCO), em 1990, e a Declaração de Salamanca, em 1994. Estas declarações tiveram reflexo direto na legislação brasileira, instituindo-se, em 2001, as Diretrizes Nacionais para a Educação Especial na Educação Básica (Resolução CNE/CEB n02/2001). Foram estas diretrizes que determinaram o real advento da educação inclusiva no país, pois o atendimento aos alunos com necessidades educacionais especiais (NEE) passa a "ser realizado em classes comuns do ensino regular, em qualquer etapa ou modalidade da Educação Básica" (BRASIL, 2001, s/p). Além disso, determina que "os sistemas de ensino devem matricular todos os alunos, cabendo às escolas organizarem-se para o atendimento aos educandos com necessidades educacionais especiais, assegurando as condições necessárias para uma educação de qualidade para todos" (BRASIL, 2001, s/p).

Desta maneira as escolas passam a ter o dever de receber todas as crianças, mas seu espaço físico pode não estar adequado para tal. Por isso, em 2004 foi assinado o Decreto $n^{\circ} 5.296$ (BRASIL, 2004), que, dentre outros aspectos, estabeleceu prazo de 30 meses para adequação das construções de uso público no Brasil à acessibilidade, conforme a NBR 9050, que estabelece critérios de acessibilidade a edificações, mobiliário, espaços e equipamentos urbanos.

No intuito de observar o processo de adaptação das escolas a esta realidade, objetiva-se avaliar a acessibilidade arquitetônica em uma escola fundamental da rede municipal no município de Colatina-ES, através de uma Avaliação Pós-Ocupação (APO).

\section{ESCOLA, INCLUSÃO E ACESSIBILIDADE ARQUITETÔNICA}

A escola é palco da construção de saberes, trocas entre pessoas, regulação de condutas e interação de indivíduos de diferentes culturas, valores e crenças (ARAÚJO et al., 2016). É considerada um "[...] resultado da expressão cultural de uma comunidade, por refletir e expressar aspectos que vão além de sua materialidade" (KOWALTOWSKI, 2011, p.11).

Partindo deste princípio, e considerando a questão da inclusão das pessoas com deficiência ou mobilidade reduzida, a escola amplia seus desafios. Considerada um processo mundial e um novo paradigma, a inclusão envolve seis dimensões de acessibilidade - arquitetônica, comunicacional, metodológica, instrumental, programática e atitudinal (SASSAKI, 2005).

Dentre estes aspectos destaca-se a "[...] incorporação dos conceitos de autonomia, independência e empoderamento nas relações entre todas as pessoas que compõem cada comunidade escolar", assim como a adoção de "[...] práticas baseadas na valorização da diversidade humana, no respeito 
pelas diferenças individuais, no desejo de acolher todas as pessoas [...]" (SASSAKI, 2005, p. 23).

Assim, entendida como conceito norteador de pedagogias atuais, a questão da acessibilidade no ambiente escolar não pode faltar em uma discussão sobre a arquitetura escolar, visto que é fundamental para a inclusão social de pessoas com diferentes habilidades (KOWALTOWSKI, 2011).

Principal usuário da escola, o aluno, possui necessidades educacionais e emocionais específicas, cujas peculiaridades variam ainda conforme a idade (KOWALTOWSKI, 2011). Neste cenário se destacam os alunos que possuem alguma deficiência pois requerem cuidados específicos.

Se o ambiente se ajusta às necessidades do usuário, torna-se mais confortável, mas se, ao ser concebido o ambiente construído não considerou-se as necessidades humanas, ele pode se tornar inóspito (CAMBIAGHI, 2012). Ultrapassando a questão do atendimento às normas de acessibilidade, 0 desenho universal busca "projetar para todos" garantindo aos usuários que possam "[...] desfrutar dos ambientes sem receber um tratamento discriminatório por causa de suas características pessoais." (CAMBIAGHI, 2012, p.81).

Mas, de maneira geral, entende-se que a acessibilidade está inserida na aplicação do Desenho Universal. Para a equiparação das possibilidades de uso do espaço por todas as pessoas, deve-se possibilitar o acesso e uso dos ambientes por meio de diferentes equipamentos, como rampas, elevadores e plataformas em locais apropriados (KOWALTOWSKI, 2011).

\section{METODOLOGIA}

Esta pesquisa realizou uma APO em uma Escola Municipal de Ensino Fundamental, selecionada por possuir o maior número de estudantes com NEE dentre as escolas da rede pública municipal do perímetro urbano de ColatinaES.

Para realização desta APO foi utilizada uma abordagem qualitativa multimétodo, considerando pareceres de técnicos (especialistas) e a satisfação dos usuários em relação ao espaço (GÜNTHER; ELALI; PINHEIRO, 2008), tendo como foco o Desenho Universal.

O percurso metodológico adotado (Figura 1) compreendeu quatro etapas: revisão bibliográfica concomitante à definição do local a ser estudado e do público-alvo; definição dos instrumentos a serem aplicados e elaboração de seus roteiros; aplicação dos instrumentos metodológicos (concepção, prétestes, análise, correções, nova aplicação; e análise dos resultados.

A equipe técnica desta pesquisa foi interdisciplinar, composta por duas arquitetas urbanistas e uma psicóloga, além de dois estudantes de graduação do curso de arquitetura e urbanismo. O estudo foi autorizado pelo Comitê de Ética em Pesquisa do Instituto Federal do Espírito Santo (CEP IFES), parecer $\mathrm{n}^{\circ}$ 2.424.446. Foram recolhidos os Termos de Consentimento Livre e Esclarecido (TCLE) dos responsáveis pelos alunos, e dos professores e pedagogo entrevistados, assim como os Termos de Assentimento Livre e Esclarecido (TALE) das crianças. 


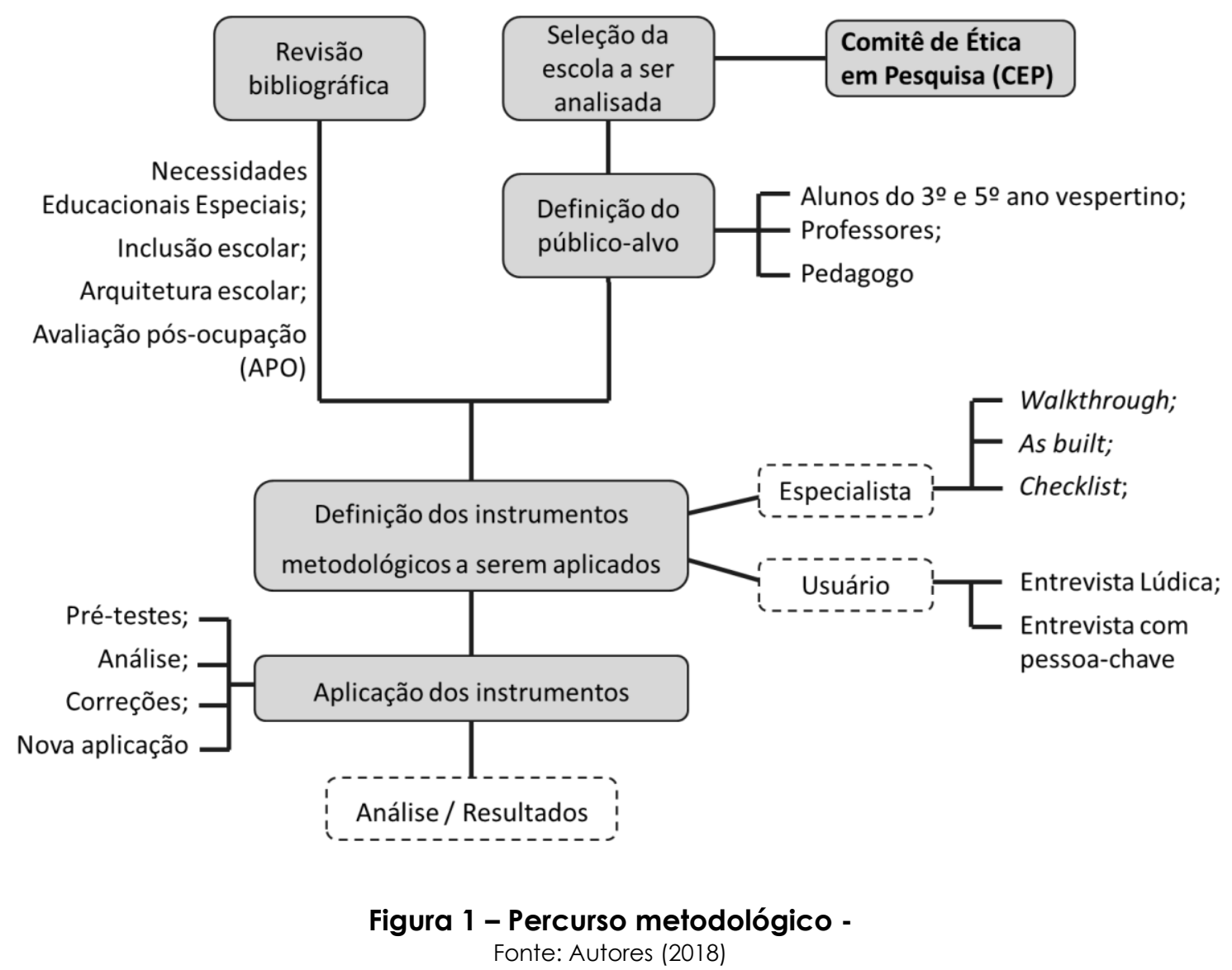

\section{RESULTADOS E DISCUSSÃO}

A escola em questão está situada em um terreno de $2.125,98 \mathrm{~m}^{2}$, possuindo $1.071,37 \mathrm{~m}^{2}$ de área construída, distribuídos em dois pavimentos. Funciona nos turnos vespertino e matutino, atendendo 340 e 318 alunos em cada turno, totalizando 658 alunos.

Para avaliação da referida escola quanto à acessibilidade e ao Desenho Universal foram aplicados instrumentos metodológicos que buscam a opinião dos especialistas (Walkthrough, As buil e Checklist) e dos usuários (Entrevista com pessoa-chave e entrevista lúdica). Tais instrumentos foram aplicados entre os meses de abril e maio de 2018, contando com a participação de 26 alunos do $3^{\circ}$ ano fundamental vespertino (entre 8 e 9 anos) - turma selecionada devido a maior quantidade de alunos com NEE (5) da escola -, e seis funcionários (cinco professores e um pedagogo).

Após a aplicação dos instrumentos, os dados obtidos foram tabulados e analisados, gerando os resultados que serão apresentados a seguir.

\subsection{Walkthrough}

O Walkthrough é uma visita de reconhecimento geral do local a ser avaliado e seus usos, de caráter exploratório (ONO et al., 2018). Ocorre, preferencialmente acompanhado por pessoas-chave, sendo definido por Rheingantz et al. (2009, p.12) como um "percurso dialogado, complementado por fotografias, croquis gerais e gravação de áudio e de vídeo". 
A aplicação do walkthrough aconteceu nos dias 04/04/2018 e 10/04/2010, entre as 13:30h e 16:30h, horário em que acontecem as aulas do turno vespertino. Os registros foram feitos em forma de anotações, croquis e fotos.

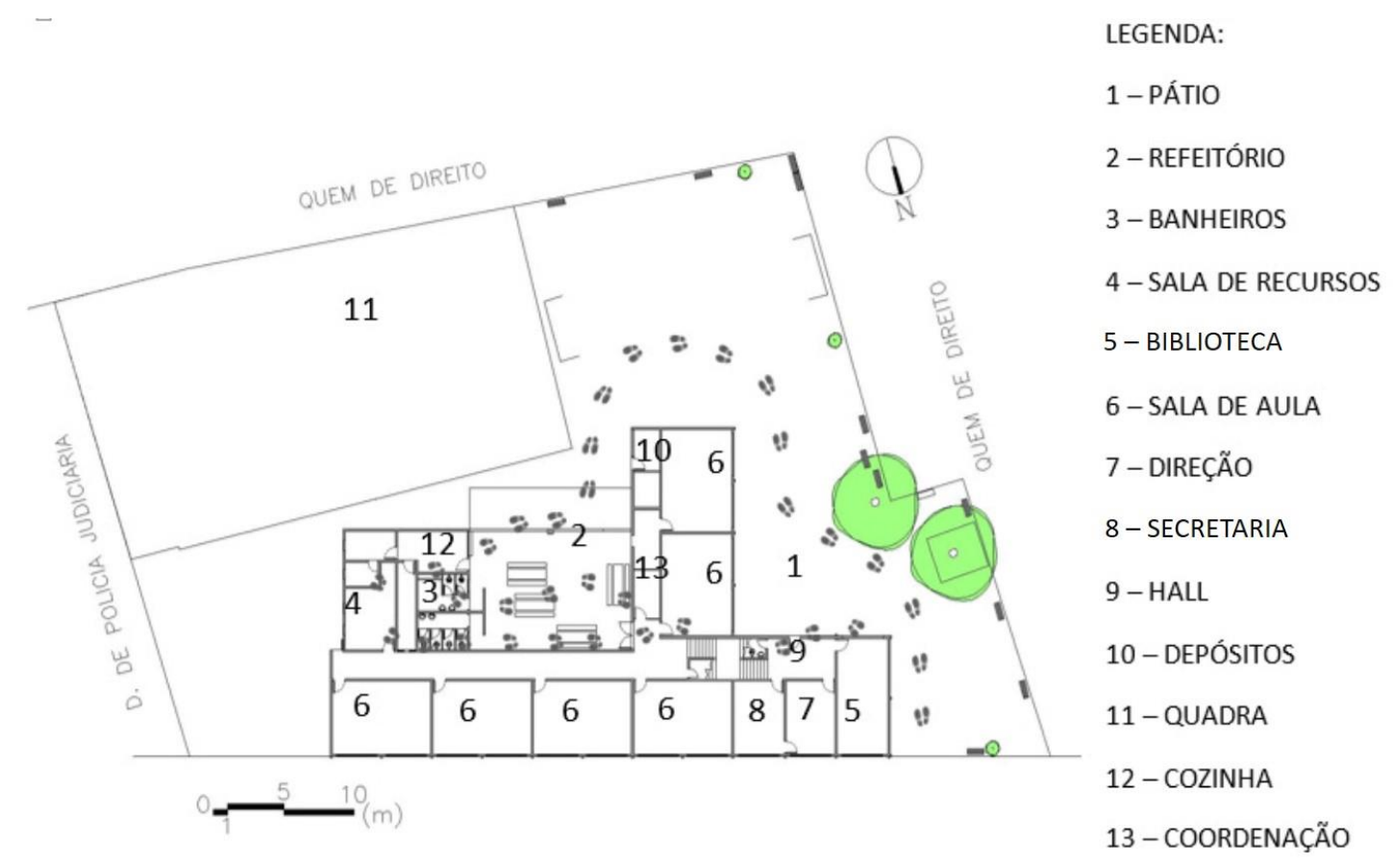

Figura 2 - Percurso do Walkthrough no primeiro pavimento Fonte: Autores (2018)

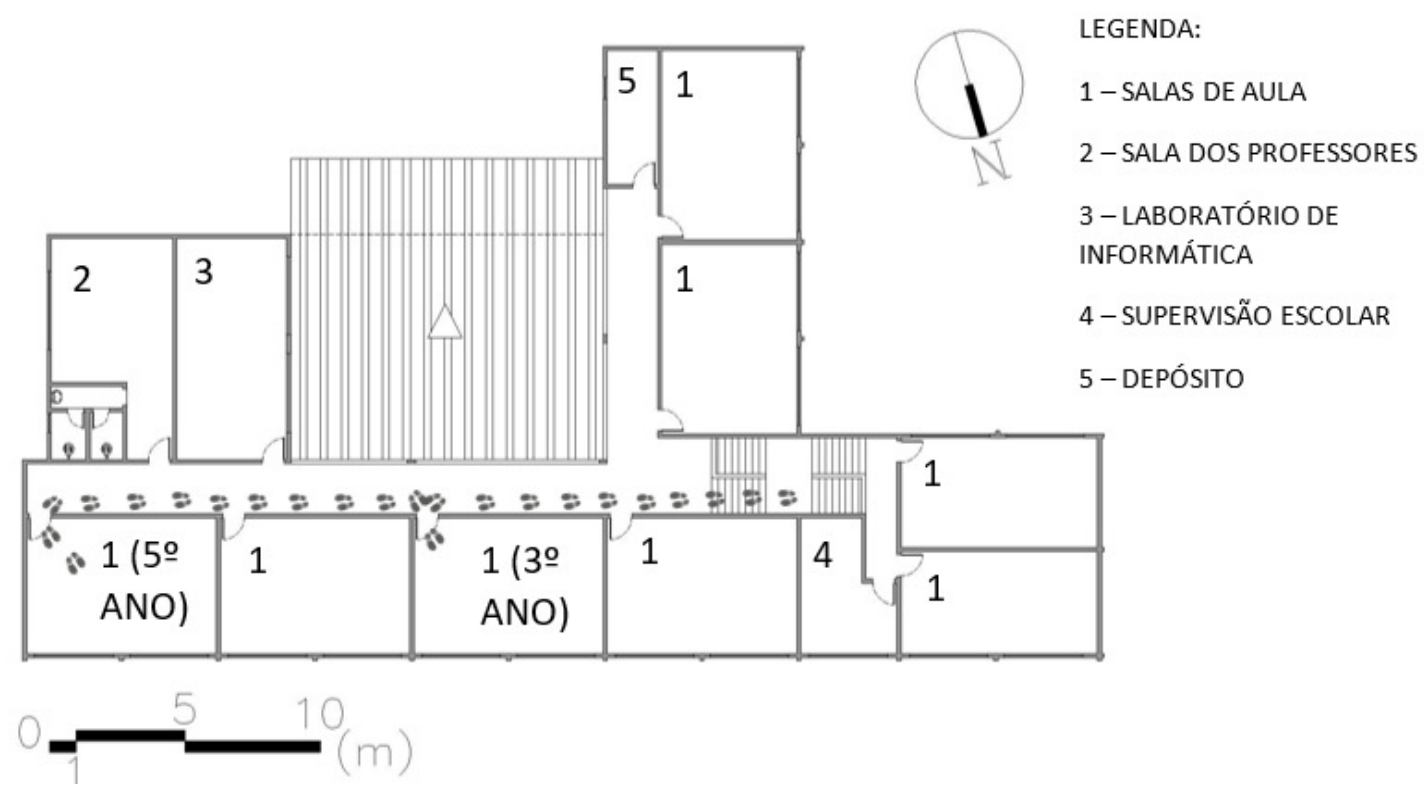

Figura 3 - Percurso do Walkthrough no segundo pavimento -

Fonte: Autores (2018)

O percurso se iniciou pelo pátio (Figura 2), onde se localiza a quadra e em seguida acessou-se a edificação. A transição do pátio para o interior da escola acontece pelo refeitório e os materiais usados nos pisos das áreas em comum geram a trepidação, possui desníveis ou são escorregadios. A 
circulação vertical acontece exclusivamente por escadas, e no segundo pavimento (Figura 3), foram percorridos circulação e duas salas de aula.

Nas salas de aulas onde estudam alunos menores em estatura, as cadeiras e mesas se adéquam aos usuários, favorecendo a ergonomia, entretanto, nos demais ambientes, como refeitório e biblioteca, os mobiliários são de tamanho convencional, não apropriado para todos os estudantes.

\subsection{As built}

O As built é um instrumento de verificação que busca averiguar as condições atuais do edifício de acordo com o os projetos originais, visando detectar possíveis mudanças realizadas durante a execução da obra ou durante o uso (ISSA; POLTRONIERI; ORNSTEIN, 2008).

Através do levantamento documental ${ }^{1}$, foi possível ter acesso a três projetos da escola. O primeiro sem data especificada, de aproximadamente 1971 de acordo com a direção da escola. O segundo projeto, de 2001, contém as plantas baixas para construção de uma nova biblioteca e sala de aula, que não foram executadas, e por fim, um arquivo digital, em AutoCad®, com o levantamento arquitetônico da escola na condição atual.

Em nenhum dos projetos houve atendimento a NBR 9050 (ABNT, 2015), a acessibilidade não fez parte da concepção da escola e a mesma não recebeu nenhum tipo de planejamento de readequação neste sentido.

\subsection{Checklist}

O Checklist é uma lista de verificação ou um roteiro técnico com uma lista dos itens a serem vistoriados, geralmente para temas e tipos de ambientes específicos, que permite avaliar de forma eficiente e produtiva um edifício, visto que determina o que deve ser avaliado e observado, otimizando o tempo de avaliação in loco (KOWALTOWSKI et al., 2013).

A aplicação ocorreu nos dias 17/04/2018 e 01/05/2018, durante as aulas do turno vespertino. As informações foram registradas em uma ficha, facilitando a conferência dos elementos elencados a partir da NBR 9050:2015 (ABNT, 2015) para os principais ambientes da escola: pátio, refeitório, salas de aula, banheiros e biblioteca, e passeio público.

Foram encontradas várias inconformidades com a norma em todos os ambientes analisados. O passeio público não atende à NBR; o portão de acesso à escola não possui maçaneta; o interfone não pode ser acessado por cadeirantes devido a sua altura e não possui tecnologia assistiva para surdos e/ou mudos.

Na edificação não existem rotas e nem planos e mapas acessíveis; o chão do pátio é trepidante; existem desníveis entre quase todos os ambientes da escola; e a circulação vertical só acontece por meio de escadas (Figura 4).

Não existem banheiros acessíveis com entrada individual e os existentes não atendem à NBR 9050/2015. E as janelas não permitem contato visual do cadeirante com o ambiente externo em nenhum dos ambientes.

\footnotetext{
' Levantamento da memória do projeto arquitetônico e possíveis modificações.
} 

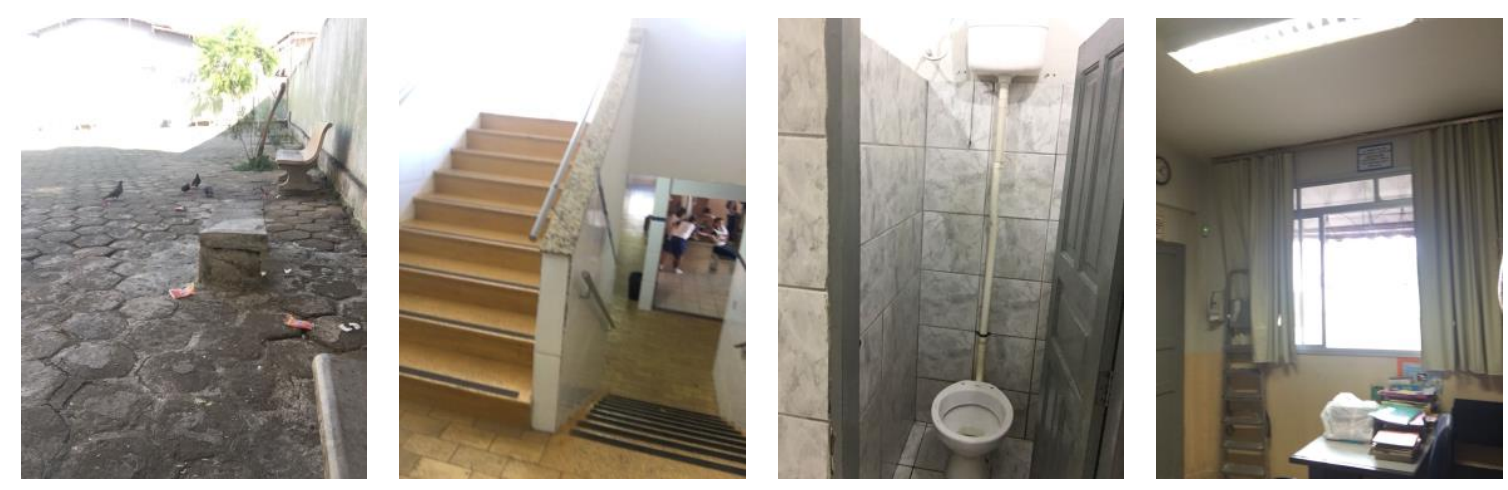

Figura 4 - Alguns ambientes escolares e problemas de acessibilidade -

Fonte: Autores (2018)

\subsection{Entrevista com pessoa(s)-chave}

A entrevista é uma "tradicional técnica e instrumento de pesquisa em Ciências Sociais" (GÜNTHER, 2008, p. 53) que tem como propósito "obter informações sistemáticas em diferentes áreas do conhecimento, sendo considerada de grande valia para compreender a interação pessoa-ambiente (ONO et al., 2018, p.124). Quando semiestruturada, o pesquisador elabora um roteiro previamente, mas as perguntas não são necessariamente aplicadas na ordem em que aparecem no roteiro, e tem-se a liberdade de adicionar perguntas a medida em que a entrevista se desenrola, buscando investigar uma ou outra questão relevante que venha a surgir (RHEINGANTZ et al., 2009).

No caso das entrevistas com pessoa(s)-chave, busca-se pessoas que são referência no local investigado, usuários que possuem informações decisivas "sobre a instituição, seu funcionamento, e o edifício em si [, bem] como sobre seus usuários e a interação pessoa-ambiente do local" (ONO et al., 2018, p.125).

As entrevistas com pessoas chave visaram obter a opinião sobre as características do ambiente construído, quanto à acessibilidade. Foram aplicadas em abril de 2018, no próprio ambiente escolar - sala dos professores e coordenação, onde foram entrevistados quatro professores e um pedagogo, com duração de 10 a 20 minutos para cada entrevistado.

Os entrevistados consideraram que os acessos e circulações da escola não são acessíveis para todos os usuários, pois a edificação não é só térrea, tem um segundo piso, e não apresenta rampa e/ou elevador para seu acesso. Diante disso, relataram que a escola não teria como atender um aluno/funcionário com deficiência física ou mobilidade reduzida, visto que o segundo piso abriga sala dos professores, coordenadoria e salas de aula.

Os banheiros também não foram considerados acessíveis, e os entrevistados os descreveram da seguinte forma: muito pequeno; insuficiente para a demanda da escola; cabine muito apertada; acessórios antigos.

O tamanho das salas de aula foi avaliado como pequeno e insuficiente para a quantidade de alunos existentes - em torno de 27 alunos por turma. As salas são as mesmas para 0 ensino do $1^{\circ}$ seguimento (crianças) e $0 \quad 2^{\circ}$ (adolescentes), não sendo adequadas para a necessidade dos mesmos. Em uma entrevista foi relatado tal fato "Não se compara alunos do $1^{\circ}$ seguimento com do $2^{\circ}$ que são adolescentes, então, seria sala para estar comportando nos anos iniciais, no máximo 25 alunos, assim, ainda ficaria cheia. E anos finais, 
22 alunos, mas temos 27, nem conseguimos circular na sala". Ressalta-se que as salas de aula têm armários e estagiários para acompanhar os alunos com $\mathrm{NEE}$, o que restringe ainda mais o espaço.

Foi apontado ainda um problema de fluxo, definido pelo acesso às salas de aula, que necessariamente ocorre pelo refeitório causando uma aglomeração dos alunos nos horários de pico - entrada/saída e horário do recreio.

\subsection{Entrevista lúdica}

A Entrevista lúdica consiste em uma entrevista que utiliza brinquedos para promover a aproximação entre o pesquisador e a criança, e estabelecer um vínculo de confiança entre eles (ABERASTURY, 1982). O instrumento em si consiste na realização de perguntas enquanto a criança se distrai com algum brinquedo, desenha ou realiza qualquer outra atividade artística (QUEIROZ, 2019).

A entrevista lúdica foi realizada durante o mês de junho de 2018, na biblioteca da escola, com grupos de três, atingindo um total de 21 alunos. Na hora da aplicação percebeu-se que realizar as perguntas enquanto as crianças brincavam era inviável, pois, por se tratar de grupos de três alunos, tornou-se complicado identificar quem respondia à pergunta, além de alguns alunos copiarem a resposta do colega. Dessa forma, optou-se por realizar as perguntas para um aluno enquanto os outros dois brincavam, revezando-se as crianças.

Os resultados indicaram que $33,3 \%$ dos alunos sentem dificuldade em caminhar pelo pátio, e $15 \%$ pelo banheiro. O pátio possui piso de cimento grosso, sem acabamento final, apresentando alguns buracos; e o banheiro é subdimensionado, apresentando-se muito cheio nos horários de intervalo e não comportando a quantidade de alunos.

\subsection{Diagnósticos e Recomendaçōes}

Os resultados obtidos pelos diferentes instrumentos aplicados foram sintetizados no Quadro 2, identificando assim, para cada aspecto e ambiente as devidas recomendações. Trata-se de um quadro-síntese de diagnósticos e recomendações, considerada uma "forma de sintetizar todas as informações obtidas por diferentes meios e fontes, num único documento" (ONO; FRANÇA; ORNSTEIN, 2018, p.136).

A partir dos resultados constata-se a inadequação dos ambientes escolares analisados. Algumas alterações na configuração do edifício e seu entorno resultariam na melhoraria da acessibilidade e no atendimento aos princípios do desenho universal, que são extremamente necessárias. Nesse sentido, pode-se citar: adequar o passeio público à legislação municipal; projetar uma entrada convidativa e que tenha espaço para acomodar os alunos na estrada e saída das aulas; implantar rotas, planos e mapas acessíveis; construir banheiros acessíveis em todos os pavimentos, além de adequar os existentes; implantar playground; adequar a escada às normas de acessibilidade e implantar plataforma elevatória; trocar o mobiliário existente por novos, adequados a escala dos estudantes e que possam ser deslocados de acordo com a atividade desenvolvida. 
Quadro 2 - Quadro-síntese de diagnósticos e recomendações

\begin{tabular}{|c|c|c|c|c|}
\hline \begin{tabular}{l|}
$\frac{0}{c}$ \\
$\frac{c}{0}$ \\
$\frac{c}{2}$ \\
0 \\
0
\end{tabular} & $\overline{0}$ & $\begin{array}{l}\text { Resultados dos métodos e técnicas aplicados } \\
\text { Walkthrough (w); As Built (ab); Checklist (c); } \\
\text { Entrevistas estruturadas com pessoas chave } \\
\text { (epc); Entrevistas lúdicas (el) }\end{array}$ & Recomendações & 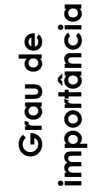 \\
\hline 음 & 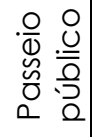 & $\begin{array}{l}\text { Não possui sinalização tátil no piso. Possui } \\
\text { desníveis e obstáculos. Não possui altura livre } \\
\text { inferior a } 2,1 \mathrm{~m}(c ; w) \text {. }\end{array}$ & Adequar às normas. & Alto \\
\hline$\stackrel{\circ}{-}$ & 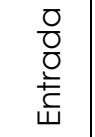 & $\begin{array}{c}\text { A entrada é apertada (epc). O interfone não } \\
\text { está na altura adequada (c). O portão não } \\
\text { possui maçaneta (c). }\end{array}$ & $\begin{array}{l}\text { Adequar dimensões da } \\
\text { entrada. Implementar } \\
\text { tecnologia assistiva. }\end{array}$ & Alto \\
\hline 은 & $\begin{array}{l}\frac{0}{0} \\
\frac{0}{0} \\
0\end{array}$ & $\begin{array}{c}\text { Dificuldade de caminhar (el). Piso com desnível e } \\
\text { trepidante. Não existem planos e mapas } \\
\text { acessíveis e sinalização tátil no piso }(c ; w) \text {. }\end{array}$ & $\begin{array}{c}\text { Implementar rota } \\
\text { acessível. }\end{array}$ & Alto \\
\hline$\stackrel{\circ}{-}$ & 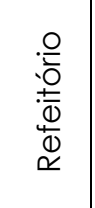 & $\begin{array}{l}\text { Apertado. Problemas de fluxo, aglomeração - } \\
\text { acesso pátio / salas de aula (epc). Mobiliário } \\
\text { inadequado e não flexível. Bebedouros em } \\
\text { desacordo com a NBR. Não existe balcão de } \\
\text { atendimento acessível na cantina }(c ; w) \text {. }\end{array}$ & $\begin{array}{l}\text { Adequar mobiliário, } \\
\text { layout, bebedouros e } \\
\text { altura balcão. }\end{array}$ & Alto \\
\hline$\stackrel{\circ}{-}$ & 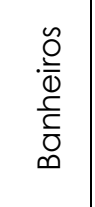 & $\begin{array}{c}\text { Pequenos (el). Não existem banheiros acessíveis } \\
\text { (epc; ab). Piso escorregadio. Não existem barras } \\
\text { de apoio para uso do lavatório e do sanitário. } \\
\text { Não existe área de aproximação de pessoas em } \\
\text { cadeira de rodas }(c ; w) .\end{array}$ & $\begin{array}{c}\text { Construir banheiro } \\
\text { acessível. }\end{array}$ & Alto \\
\hline$\stackrel{\circ}{-}$ & $\begin{array}{l}0 \\
0 \\
0 \\
\frac{0}{0} \\
\frac{0}{0}\end{array}$ & $\begin{array}{l}\text { Apertada. Não comporta uma turma (epc). Não } \\
\text { existem corredores para acesso aos livros. } \\
\text { Abertura da janela em desacordo com o cone } \\
\text { visual de uma pessoa em cadeira de rodas. Os } \\
\text { interruptores não estão em altura acessível (c; w). }\end{array}$ & $\begin{array}{l}\text { Reorganizar layout para } \\
\text { acesso aos livros. } \\
\text { Substituir esquadrias e } \\
\text { adequar altura dos } \\
\text { interruptores. }\end{array}$ & Alto \\
\hline & 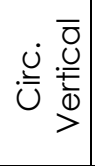 & $\begin{array}{c}\text { Acesso apenas por escadas (epc). Dificuldade } \\
\text { em subir, degrau alto (el). Corrimão em } \\
\text { desacordo com a norma e ausência de piso tátil } \\
\text { para sinalização da escada }(c ; w) \text {. }\end{array}$ & $\begin{array}{l}\text { Instalar rampa ou } \\
\text { elevador. Adequar } \\
\text { escada existente. }\end{array}$ & Alto \\
\hline$\stackrel{\sim}{\circ}$ & $\begin{array}{l}\frac{0}{2} \\
\frac{x}{0} \\
\frac{0}{0} \\
\frac{0}{0} \\
\frac{0}{0}\end{array}$ & $\begin{array}{l}\text { Apertada, difícil circular (epc). Não localizadas } \\
\text { em rotas acessíveis. Lousa posicionada acima do } \\
\text { recomendado e sem área de aproximação. Não } \\
\text { existe sistema de comunicação para pessoas } \\
\text { com deficiência (Braille e Libras). Abertura da } \\
\text { janela não está de acordo com o cone visual de } \\
\text { uma pessoa em cadeira de rodas. Interruptores } \\
\text { não estão em altura acessível (c; w). }\end{array}$ & $\begin{array}{l}\text { Implementar planos e } \\
\text { mapas acessíveis. Locar } \\
\text { lousa na altura indicada } \\
\text { em norma. Implementar } \\
\text { sistemas adequados de } \\
\text { comunicação. Substituir } \\
\text { esquadrias e adequar } \\
\text { altura dos interruptores. }\end{array}$ & Alto \\
\hline
\end{tabular}

Fonte: Autores (2018)

Estas diretrizes projetuais, além de proporcionar acessibilidade, aumentando a satisfação dos usuários e permitindo a inclusão, permitiriam que o ambiente escolar em questão ficasse de acordo com a legislação federal, que exige acessibilidade plena em edifícios de uso público (BRASIL, 2004).

\section{CONSIDERAÇÕES FINAIS}

Ressalta-se a importância da utilização de instrumentos de APO para diagnosticar ambientes em uso, visto que envolve percepções da relação das 
pessoas com o ambiente e apontam questões específicas de cada local, assim, além do olhar a partir de normas técnicas, tem-se a opinião dos usuários para adequações coerentes com a realidade da escola.

Nas condições atuais, este ambiente escolar priva e/ou dificulta o uso para pessoas com deficiência e mobilidade reduzida, resultando na falta de inclusão. Os impactos destas barreiras são muito mais amplos e podem gerar marcas profundas, como o sentimento de não pertencimento à comunidade escolar.

\section{AGRADECIMENTOS}

Os autores agradecem à instituição e a seus funcionários, bem como aos pais e às crianças participantes, pela confiança, e ao Instituto Federal do Espírito Santo (Ifes) pelo apoio.

\section{REFERÊNCIAS}

ABERASTURY, A. Psicanálise da Criança: teoria e técnica. Porto Alegre: Artmed, 1982.

ASSOCIAÇÃO BRASILEIRA DE NORMAS TÉCNICAS. NBR 9050: Acessibilidade de pessoas portadoras de deficiência a edificações, mobiliário, espaços e equipamentos urbanos. Rio de Janeiro, 2015.

NBR 16537: Acessibilidade - Sinalização tátil no piso - Diretrizes para elaboração de projetos e instalação. Rio de Janeiro, 2016.

ARAÚJO, P. V.; PESSOA, V. S.; FONSECA, P. N.; ALBUQUERQUE, J. H. A.; ALMEIDA, A. C. Eu gosto da escola: um estudo sobre apego ao ambiente escolar. In:

Psicologia Escolar e Educacional, v. 20, n. 2, 2016, p. 377-384.

BRASIL. Resolução CNE/CEB $\mathbf{n}^{\circ}$ 2, de 11 de setembro de 2001. Institui Diretrizes Nacionais para a Educação Especial na Educação Básica. Disponível em: <http://portal.mec.gov.br/cne/arquivos/pdf/CEB0201.pdf>. Acesso em: 11 nov, 2018.

Decreto $n^{\circ}$ 5.296, de 2 de dezembro de 2004. Disponível em:

$<$ http://www.planalto.gov. br/ccivil_03/_ato2004-

2006/2004/decreto/d5296.htm>. Acesso em: 10 fev. 2019.

CAMBIAGHI, S. Desenho universal: métodos e técnicas para arquitetos e urbanista. 3 ed rev. São Paulo: Editora Senac São Paulo, 2012.

GÜNTHER, H.; ELALI, G. A.; PINHEIRO, J. Q. A abordagem multimétodos em Estudos Pessoa-Ambiente: características, definições e implicações. In: PINHEIRO, J. Q.; GÜNTHER, H. (Org). Métodos de pesquisa nos estudos pessoaambiente. São Paulo: Casa do Psicólogo, 2008. p.369-396.

GÜNTHER, I. A.; O uso da entrevista na interação pessoa-ambiente. In: PINHEIRO, J. Q.; GÜNTHER, H. (Org). Métodos de pesquisa nos estudos pessoaambiente. São Paulo: Casa do Psicólogo, 2008. p.53-74.

ISSA, M. P.; POLTRONIERI, J. P.; ORNSTEIN, S. W. Procedimentos para avaliação pós-ocupação (APO) de edifícios escolares: o caso da E.E. Fernando Gasparian, na cidade de São Paulo. Anais... São Paulo: NUTAU-USP, 2008. 
KOWALTOWSKI, D. Arquitetura escolar. O projeto do ambiente de ensino. São Paulo: Oficina de Textos, 2011.

KOWALTOWSKI, D. C. C. K.; GRANJA, A. D.; MOREIRA, D. C.; SILVA, V. G.; PINA, S. A. M. G. Métodos e instrumentos de avaliação de projetos destinados à habitação de interesse social. In: VILLA, S. B.; ORNSTEIN, S. W. (orgs.). Qualidade Ambiental na habitação: avaliação pós-ocupação. São Paulo: Oficina de Textos, 2013. p.149-184.

ONO, R.; VILLA, S. B.; ABATE, T. P.; BARBOSA, M. B. P.; FRANÇA, A. J. G. L.; ORNSTEIN, S. W. Métodos qualitativos para a aferição da percepção dos usuários. In: ONO, R.; ORNSTEIN, S. W.; VILLA, S. B.; FRANÇA, A. J. G. L. Avaliação pós-ocupação: na arquitetura, no urbanismo e no design: da teoria à prática. São Paulo: Oficina de Textos, 2018. p.121-134.

ONO, R.; FRANÇA, A. J. G. L; ORNSTEIN, S. W. Formas de apresentação dos resultados. In: ONO, R.; ORNSTEIN, S. W.; VILLA, S. B.; FRANÇA, A. J. G. L.

Avaliação pós-ocupação: na arquitetura, no urbanismo e no design: da teoria à prática. São Paulo: Oficina de Textos, 2018. p.135-146.

QUEIROZ, V. M. Qualidade espacial para pessoas com deficiência intelectual: investigando modos de obter a opinião de crianças pequenas com Síndrome de Down. 2019. 278 p. Tese (Doutorado em Arquitetura e Urbanismo) Faculdade de Arquitetura e Urbanismo, Universidade de São Paulo, São Paulo, 2019.

RHEINGANTZ, P. A.; AZEVEDO, G. A.; BRASILEIRO, A.; ALCÂNTARA, D.; QUEIROZ, M. Observando a qualidade do lugar: procedimentos para a avaliação pósocupação. Rio de Janeiro: Universidade Federal do Rio de Janeiro, Faculdade de Arquitetura e Urbanismo, Pós-Graduação em Arquitetura, Rio de Janeiro: PROARQ/UFRJ, 2009. $118 \mathrm{p}$.

SASSAKI, R. K. Inclusão: o paradigma do século 21. Revista Inclusão, ano I, n. 1, out. 2005, p. 19-23. Disponível em:

<http://portal.mec.gov.br/seesp/arquivos/pdf/revistainclusao 1.pdf>. Acesso em: 9 jun. 2019. 